\title{
Aetiology and Clinical Profile of Giant Left Atrium - An Observational Study.
}

\author{
AKM Monwarul Islam ${ }^{1}$, A.A.S. Majumder ${ }^{1}$, Shovan Rahman ${ }^{1}$, Kaniz Ananya ${ }^{1}$, Tanveer \\ Ahmad $^{2}$, and Bijoy Dutta ${ }^{1}$ \\ ${ }^{1}$ National Institute of Cardiovascular Diseases \\ ${ }^{2}$ United Hospital Ltd.
}

August 8, 2021

\begin{abstract}
Background: The predominant cause of giant left atrium (GLA) is rheumatic mitral valvular disease. GLA is commonly defined echocardiographically by measuring the left atrial diameter (LAD). In the context of changing epidemiology of rheumatic heart disease (RHD) globally, and introduction of left atrial volume index (LAVI), the aetiology of GLA and utility of LAVI for defining GLA may be necessary. Methods: The prospective observational study was carried out at a dedicated tertiary care cardiac centre of a developing country to know the aetiology and clinical pattern of GLA over 8 years. GLA was defined echocardiographically as a left atrium (LA) having a diameter [?]80 mm in the left parasternal long-axis view. Follow-up was made over the telephone. Results: Thirty cases of GLA were diagnosed over 8 years from 2013 to 2021. Twenty two were due to rheumatic heart disease (RHD), 7 due to MVP, and 1 due to flail anterior mitral leaflet. Mean LAD was $92.13 \pm 16.72 \mathrm{~mm}$, and the mean LAVI was $288.77 \pm 134.40 \mathrm{ml} / \mathrm{m} 2$. LA thrombus was present in 5 patients, 6 had spontaneous echo contrast (SEC) in LA, 2 had both LA thrombus and SEC. Mean follow-up was $0.99 \pm 1.06$ years. Out of 15 patients, 5 died, while 10 were alive. Mean survival was $1.8 \pm 1.17$ years, ranging from less than 1 year to 4 years. Conclusion: RHD continues to be the predominant cause of GLA; however, MVP is also important. The cut-off value of LAVI for defining GLA needs further study.
\end{abstract}

Title: Aetiology and Clinical Profile of Giant Left Atrium - An Observational Study. Authors' Name \& Affiliations:

AKM Monwarul Islam MD, FCPS, FACC, FESC, FASE, FACP, FRCP,Associate Professor, Department of Cardiology, National Institute of Cardiovascular Diseases, Dhaka, Bangladesh. Email:drmonwarbd@yahoo.com

Abdullah AS Majumder MD, D Card, FACC, FESC, FSCAI, FCSI, FRCP,Ex-Director and Professor, National Institute of Cardiovascular Diseases, Dhaka, Bangladesh. Email:m.abdullaalshafi@yahoo.com

Shovan Rahman FCPS, MRCP, Medical Officer, Department of Cardiology, National Institute of Cardiovascular Diseases, Dhaka, Bangladesh. Email:dr.shovan42@gmail.com

Kaniz Fatema Ananya FCPS, Medical Officer, Department of Cardiology, National Institute of Cardiovascular Diseases, Dhaka, Bangladesh. Email:ananyazaman@gmail.com

Tanveer Ahmad MD, Specialist, Department of Cardiology, United Hospital Ltd., Dhaka, Bangladesh. Email:

tanveer_sami@yahoo.com

Bijoy Dutta MD, Assistant Professor, Department of Cardiology, National Institute of Cardiovascular Diseases, Dhaka, Bangladesh. Email:bijoy_k51@yahoo.com 


\title{
Dr. AKM Monwarul Islam MD
}

Associate Professor,

Department of Cardiology,

National Institute of Cardiovascular Diseases,

Dhaka 1207, Bangladesh.

Telephone: +8801712564487 (Mobile)

Email: drmonwarbd@yahoo.com.

Aetiology and Clinical Profile of Giant Left Atrium - An Observational Study.

\begin{abstract}
:
Background: The predominant cause of giant left atrium (GLA) is rheumatic mitral valvular disease. GLA is commonly defined echocardiographically by measuring the left atrial diameter (LAD). In the context of changing epidemiology of rheumatic heart disease (RHD) globally, and introduction of left atrial volume index (LAVI), the aetiology of GLA and utility of LAVI for defining GLA may be necessary.
\end{abstract}

Methods : The prospective observational study was carried out at a dedicated tertiary care cardiac centre of a developing country to know the aetiology and clinical pattern of GLA over 8 years. GLA was defined echocardiographically as a left atrium (LA) having a diameter [?]80 $\mathrm{mm}$ in the left parasternal long-axis view. Follow-up was made over the telephone.

Results : Thirty cases of GLA were diagnosed over 8 years from 2013 to 2021. Twenty two were due to rheumatic heart disease (RHD), 7 due to MVP, and 1 due to flail anterior mitral leaflet. Mean LAD was $92.13 \pm 16.72 \mathrm{~mm}$, and the mean LAVI was $288.77 \pm 134.40 \mathrm{ml} / \mathrm{m}^{2}$. LA thrombus was present in 5 patients, 6 had spontaneous echo contrast (SEC) in LA, 2 had both LA thrombus and SEC. Mean follow-up was 0.99 \pm 1.06 years. Out of 15 patients, 5 died, while 10 were alive. Mean survival was $1.8 \pm 1.17$ years, ranging from less than 1 year to 4 years.

Conclusion : RHD continues to be the predominant cause of GLA; however, MVP is also important. The cut-off value of LAVI for defining GLA needs further study.

Key words: Left Atrium, Dilatation, Transthoracic Echocardiography, Aetiology, Thrombus.

Introduction:

Giant left atrium (GLA) is a rare condition with a reported prevalence of only $0.3-0.6 \% .{ }^{1-4}$ It has variably been defined as a left atrium (LA) having a cardiothoracic ratio (CTR) of [?]0.7 in chest x-ray, or left atrial diameter (LAD) of [?]65 $\mathrm{mm}$ or [?]80 $\mathrm{mm}$ in transthoracic echocardiography (TTE). ${ }^{2,4}$ It is typically found in rheumatic mitral valvular disease (MVD), but has also been described in association with a myriad of non-rheumatic conditions. ${ }^{1,2,5}$ Globally, over the past decades, the epidemiology of rheumatic fever and rheumatic heart disease (RHD) has changed considerably with a marked decline in prevalence ${ }^{6,7}$, and hence, the aetiology of GLA might change accordingly. Irrespective of the underlying aetiology, the clinical importance of GLA lies in its potential for causing heart failure, compression effect on the nearby structures, atrial fibrillation (AF), and facilitating thrombus formation. ${ }^{1,2,5}$ Also, despite the popularity of using LAD to define GLA, the left atrial volume index (LAVI) might be a better parameter in this regard. ${ }^{2}$ The present study was carried out to determine the aetiology and clinical profile of GLA encountered over 8 years in a tertiary care cardiac hospital of a developing country.

\section{Methods}

This was a single-centre, prospective, observational study carried out in the Department of Cardiology, National Institute of Cardiovascular Diseases (NICVD), Dhaka, Bangladesh, over 8 years from 2013 to 2021. The study protocol was approved by the Institutional Review Board of the Institute. Informed consent was 
taken from the participants. All patients diagnosed with GLA due to any cause over the above-mentioned period at NICVD were included in the study. GLA was defined as an LA having an anteroposterior diameter [?]80 mm in parasternal long axis (PLAX) view of conventional transthoracic echocardiography (TTE). In cases with repeated examinations, the initial one was selected.

Echocardiographic examination was carried out by the Vivid 7 and Vivid E95 echocardiography machine (GE Healthcare, 9900 Innovation Drive, Wauwatosa, WI 53226, USA). The examination was carried out as per the recommendation of the American Society of Echocardiography. ${ }^{8,9}$ LA volume was determined by Simpson's biplane method. LAVI was calculated by dividing the LA volume by the body surface area. The severity of valvular regurgitation and stenosis, as well as the mitral valve prolapse (MVP), were defined according to current guidelines. ${ }^{10,11}$ The end-point for follow-up comprised of all-cause death. The patient or the relatives were contacted over the phone.

\section{Results:}

Thirty cases of GLA were diagnosed over 8 years from 2013 to 2021 and included in the study. Out of 30 cases, 14 were male, and 16 were female. The mean age of the patients was $37.67+-11.22$ years. The youngest patient was a 16-year-old female with MVP who presented with severe mitral regurgitation (MR). (Table 1) The oldest patient was a 59-year-old male who also had MVP with severe MR. (Table 1) The underlying aetiology was RHD (Figure 1) in 22 cases, MVP (Figure 2) in 7 cases, and flail anterior mitral leaflet (AML) in 1 case. Among the RHD cases, isolated mitral stenosis (MS), isolated MR, mixed mitral valvular disease comprising of MS and MR, and multiple valvular disease comprising of mitral and aortic valvular disease were the underlying lesions in 3, 3, 7, and 9 cases, respectively. Among these patients, 1 had a history of percutaneous transvenous mitral commissurotomy (PTMC), 1 had a history of closed mitral commissurotomy (CMC), and 2 patients had mitral valve replacement (MVR). Out of 30 GLA cases, 16 had severe MR - 8 due to RHD, 7 due to MVP, and 1 due to flail AML. So, all MVP and the only flail AML cases presented with severe MR. Few patients with MVP were wrongly diagnosed as RHD for long before making the correct diagnosis. All cases presented with heart failure, on top of which 1 patient had dilated cardiomyopathy (DCM), and another 1 had an ischaemic stroke. None presented with Ortner's syndrome. ECG rhythm was analyzed in 28 cases; sinus rhythm was found in 3 patients only, permanent AF was present in 24 cases, and paroxysmal AF in 1 patient.

Echocardiography was done in all patients; however, some lack several parameters. Mean LAD was 92.13 +- $16.72 \mathrm{~mm}$, ranging from $80 \mathrm{~mm}$ to $161 \mathrm{~mm}$. The longest $161 \mathrm{~mm}$ LAD was found in a 52-year-old male patient with MVP and severe MR. LAVI was determined in 17 patients. The mean LAVI was $288.77+-$ $134.40 \mathrm{ml} / \mathrm{m}^{2}$, ranging from $161 \mathrm{ml} / \mathrm{m}^{2}$ to $605 \mathrm{ml} / \mathrm{m}^{2}$. The highest LAVI was found in a 35-year-old male patient having a history of MVR, severe MR, and moderate aortic regurgitation (AR). Mean pulmonary artery systolic pressure (PASP) was $64.5+-28.72 \mathrm{mmHg}$. Right ventricular (RV) function was recorded in all but 1 patient. RV dysfunction characterized by tricuspid annular plane systolic excursion (TAPSE) $<16 \mathrm{~mm}$, and/or or RV tissue Doppler systolic excursion velocity (RV S') $<9.5 \mathrm{~cm} / \mathrm{sec}$ was present in 19 patients. Out of 30 patients, LA thrombus was present in 5 patients, 6 had spontaneous echo contrast (SEC) in LA, 2 patients had both LA thrombus and SEC. (Figure 3) During follow-up, 15 patients could not be contacted. The mean follow-up duration was $0.99+-1.06$ years, ranging from $<1$ month to 48 months. Out of 15 patients, 5 died, while 10 were alive. Mean survival was $1.8+-1.17$ years, ranging from less than 1 year to 4 years.

\section{Discussion:}

Definition of GLA lacks a uniform consensus. ${ }^{2,4}$ In the present study, GLA was defined as any LA having a diameter of [?] $80 \mathrm{~mm}$ in PLAX view of conventional TTE. Before the advent of medical imaging, 'extreme dilatation of the left auricle' was described by Owen and Fenton in 1901 clinically by the presence of dullness on percussion on the right chest in a 40-year-old lady with a history of rheumatic fever and subsequent post-mortem examination. ${ }^{12}$ Subsequently, a chest x-ray was used rather than the clinical method only; GLA was defined as an LA which "touched the right chest wall or extended within one centimetre of it on a 
posteroanterior chest x-ray." ${ }^{5}$ Cardiothoracic ratio (CTR) [?]0.7 was also used as a criterion for GLA. ${ }^{13}$ In the 1960s, echocardiography was introduced and became the imaging modality of choice for diagnosing GLA. LAD [?]80 mm in TTE with CTR [?]0.7 in CXR was the criterion used to define GLA by Piccoli et al. ${ }^{14}$ Even less stringent measure of LAD [?]65 mm in TTE had been used in this regard. ${ }^{15} \mathrm{LA}$ is a 3 -dimensional structure, and measurement of LAD may not be the optimum parameter to assess the enlarged LA. Here, measurement of volume rather than diameter may be a better way to study and define GLA. ${ }^{1,2}$ In this study, LAVI was determined in 17 out of 30 cases. Unfortunately, no criteria to define GLA based on LAVI are available to date. The mean LAVI was $288.77+-134.40 \mathrm{ml} / \mathrm{m}^{2}$ in the present study. The mean LAD was 89 $\mathrm{mm}$ (range $80-121 \mathrm{~mm}$ ), and the mean LA volume (not volume index) was $593.96 \mathrm{ml}$ (range $364.3 \mathrm{ml}$ to 921 $\mathrm{ml}$ ) in the study by El Maghraby and Hajar. ${ }^{2}$ On the other hand, the median LAD was $67 \mathrm{~mm}$ (range 66-71 $\mathrm{mm}$ ), and the median LAVI was $118.9 \mathrm{~mL} / \mathrm{m}^{2}$ (range $100.2-149.1 \mathrm{~mL} / \mathrm{m}^{2}$ ) in a Korean study. ${ }^{1}$ Noteworthy that the former study used the criterion of LAD [?] $80 \mathrm{~mm}$ to define GLA like the present study, whereas the latter study used the cut-off point of $65 \mathrm{~mm}$ to define GLA. In the present study, mean LAD was $92 \mathrm{~mm}$, and mean LAVI was $289 \mathrm{ml} / \mathrm{m}^{2}$; taken these values, for $80 \mathrm{~mm}$ cut-off of LAD, corresponding LAVI is 251 $\mathrm{ml} / \mathrm{m}^{2}$. Whether this cut-off value of LAVI of $\sim 250 \mathrm{ml} / \mathrm{m}^{2}$ can be used to define GLA needs further study.

Consistent with the previous case reports, case series, and studies, the predominant cause of GLA in the present study was RHD, responsible for almost $3 / 4^{\text {ths }}$ of 30 cases. However, it is noteworthy that the resting $1 / 4^{\text {th }}$ cases, i.e., 8 were due to non-rheumatic causes (MVP, flail AML). Historically, since 1901, almost all cases of GLA reported were due to RHD. The series of 10 cases of GLA described by DeSanctis et al. in 1964 from the Massachusetts General Hospital, the USA, over 30 years were all due to the RHD. Also, during that time, like ours now, RHD was not uncommon in the Western world, including the USA. However, the situation has changed, and RHD is now rare there. GLA is at present only rarely reported in the USA and is mostly involving immigrants. ${ }^{16}$ On the other hand, despite the transition in disease epidemiology, RHD is still prevalent in developing countries, including Bangladesh. ${ }^{17}$ So, logically, RHD would continue to be the dominating cause of GLA in these parts of the world. RHD was the underlying condition in the majority of cases of GLA in more recent studies; however, other causes like MVP, functional MR, hypertrophic cardiomyopathy and cardiac amyloidosis have also been identified as significant or rare causes. ${ }^{1,2,18-21}$ With further control of rheumatic fever and RHD, MVP may top the otherwise small list of aetiological diagnoses of GLA in the future.

Analysis of the pattern of valvular lesions causing GLA due to RHD, MR was the dominant lesion over MS in the majority. This observation is consistent with those of previous studies. ${ }^{2,5,13}$ Isolated MS as a cause of GLA was described only rarely in the past. ${ }^{13}$ Out of 38 cases of GLA referred for mitral valve surgery, isolated MS was found in 29\%, MR in 21\%, combined MS and MR in 50\%, and aortic pathology was associated in $45 \% .{ }^{13}$ In the present study, 3 out of 30 (i.e., $10 \%$ ) cases were due to isolated MS.

Out of 30 patients, LA thrombus was present in 5 patients, 6 had SEC in LA, 2 patients had both LA thrombus and SEC. Despite the massive LA and the common association of AF, thrombus formation is relatively infrequent in GLA. ${ }^{5}$ The underlying reason behind this apparent paradox is severe MR which tends to prevent stasis. In the present study, $43 \%$ of the cases had either thrombus or SEC in LA, and the latter is generally considered as the precursor of the former. ${ }^{22}$ Presence of a fair number of cases of MS may be the explanation of the more common occurrence of thrombus and SEC in the present series. Strikingly, embolism was relatively uncommon - only 1 patient presented with ischaemic stroke. Thromboembolism was also rarely described in previous reports. ${ }^{2,5}$

In the present study, follow-up was done mainly via telephone. Adequate information was available for 15 cases only. The mean duration of follow up was 11.88 months, ranging from $<1$ month to 48 months. Out of 15 patients, 5 died, and 10 were alive. One patient died within 1 week of double valve replacement (DVR), while 1 patient recently had DVR. Some of the GLA cases could not be contracted because of incomplete records or lack of response to the recorded phone number. This is the real-world situation, presumably in many developing countries. Despite incomplete follow-up, some observations can be made. Most of the patients did not receive surgical treatment; instead, they were managed medically. Poverty, inadequate facilities for 
surgical treatment, presence of high-risk features, and tendency to adopt less aggressive treatment strategy by the cardiac surgeons may be responsible.

The study has got some critical limitations. The follow-up was suboptimal. Out of 30 patients, only half could be traced. The underlying cause of death could not be ascertained in every case. Also, LAVI was not determined in all cases. The strength of this study is that it includes the all-comer real-world patients with an otherwise rare clinical entity. It may be one of the most extensive series of GLA cases with such stringent definition of GLA of [?] $80 \mathrm{~mm}$ reported so far. Also, some observations and recommendations have been made regarding the use of LAVI to define GLA in place of LAD, though they need further confirmation.

\section{Conclusion:}

GLA is a rare and rather heterogeneous entity. Physicians should have appropriate preparedness to deal with GLA in the present century. More information regarding GLA based on advanced imaging modalities like 3-dimensional echocardiography, cardiac computed tomography and cardiac magnetic resonance may be warranted.

What is Already Known? Giant left atrium (GLA) is commonly defined using chest x-ray or transthoracic echocardiogr What this Study Adds? Left atrial volume index (LAVI) determined by echocardiography may be a better alternative f

\section{Acknowledgments:}

The authors would like to thank the Echocardiography Unit of the National Institute of Cardiovascular Diseases, Dhaka, Bangladesh, for the wholehearted support.

\section{Funding:}

This research did not receive any specific grant from funding agencies in the public, commercial, or not-forprofit sectors.

\section{References:}

1. Kim H, Park YA, Choi SM, et al. Associates and prognosis of giant left atrium; Single-center experience. J Cardiovasc Ultrasound. 2017 Sep;25(3):84-90. doi: 10.4250/jcu.2017.25.3.84.

2. El Maghraby A, Hajar R. Giant left atrium: a review. Heart Views. 2012 Apr;13(2):46-52. doi: 10.4103/1995-705X.99227.

3. Apostolakis E, Shuhaiber JH. The surgical management of giant left atrium. Eur J Cardiothorac Surg. 2008 Feb;33(2):182-90. doi: 10.1016/j.ejcts.2007.11.003.

4. Oh JK. Echocardiographic evaluation of morphological and hemodynamic significance of giant left atrium. An important lesson. Circulation. 1992 Jul;86(1):328-30. doi: 10.1161/01.cir.86.1.328.

5. DeSanctis RW, Dean DC, Bland EF. Extreme left atrial enlargement, Some characteristic features. Circulation. 1964 Jan;29:14-23.

6. Ordunez P, Martinez R, Soliz P, et al. Rheumatic heart disease burden, trends, and inequalities in the Americas, 1990-2017: a population-based study. Lancet Glob Health. 2019 Oct;7(10):e1388-e1397. doi: 10.1016/S2214-109X(19)30360-2.

7. Seckeler MD, Hoke TR. The worldwide epidemiology of acute rheumatic fever and rheumatic heart disease. Clin Epidemiol. 2011 Feb 22;3:67-84. doi: 10.2147/CLEP.S12977.

8. Lang RM, Badano LP, Mor-Avi V, et al. Recommendations for cardiac chamber quantification by echocardiography in adults: an update from the American Society of Echocardiography and the European Association of Cardiovascular Imaging. Eur Heart J Cardiovasc Imaging. 2015 Mar;16(3):233-70. doi: $10.1093 /$ ehjci/jev014.

9. Lang RM, Bierig M, Devereux RB, et al.; Chamber Quantification Writing Group; American Society of Echocardiography's Guidelines and Standards Committee; European Association of Echocardiography. Recommendations for chamber quantification: a report from the American Society of Echocardiogra- 
phy's Guidelines and Standards Committee and the Chamber Quantification Writing Group, developed in conjunction with the European Association of Echocardiography, a branch of the European Society of Cardiology. J Am Soc Echocardiogr. 2005 Dec;18(12):1440-63. doi: 10.1016/j.echo.2005.10.005.

10. Nishimura RA, Otto CM, Bonow RO, et.; ACC/AHA Task Force Members. 2014 AHA/ACC Guideline for the Management of Patients With Valvular Heart Disease: a report of the American College of Cardiology/American Heart Association Task Force on Practice Guidelines. Circulation. 2014 Jun 10;129(23):e521-643. doi: 10.1161/CIR.0000000000000031.

11. American College of Cardiology/American Heart Association Task Force on Practice Guidelines; Society of Cardiovascular Anesthesiologists; Society for Cardiovascular Angiography and Interventions; Society of Thoracic Surgeons, Bonow RO, Carabello BA, Kanu C, et al. ACC/AHA 2006 guidelines for the management of patients with valvular heart disease: a report of the American College of Cardiology/American Heart Association Task Force on Practice Guidelines (writing committee to revise the 1998 Guidelines for the Management of Patients With Valvular Heart Disease): developed in collaboration with the Society of Cardiovascular Anesthesiologists: endorsed by the Society for Cardiovascular Angiography and Interventions and the Society of Thoracic Surgeons. Circulation. 2006 Aug 1;114(5):e84-231. doi: 10.1161/CIRCULATIONAHA.106.176857.

12. Owen I, Fenton WJ. A case of extreme dilatation of the left auricle of the heart. Trans Clin Soc London 1901;34:183-91.

13. Di Eusanio G, Gregorini R, Mazzola A, et al. Giant left atrium and mitral valve replacement: Risk factor analysis. Eur J Cardiothorac Surg. 1988;2(3):151-9. doi: 10.1016/1010-7940(88)90063-2.

14. Piccoli GP, Massini C, Di Eusanio G, et al. Giant left atrium and mitral valve disease: early and late results of surgical treatment in 40 cases. J Cardiovasc Surg (Torino). 1984 Jul-Aug;25(4):328-36.

15. Minagoe S, Yoshikawa J, Yoshida K, et al. Obstruction of inferior vena caval orifice by giant left atrium in patients with mitral stenosis. A Doppler echocardiographic study from the right parasternal approach. Circulation. 1992 Jul;86(1):214-25. doi: 10.1161/01.cir.86.1.214.

16. Hurst JW. Memories of patients with a giant left atrium. Circulation. 2001 Nov 27;104(22):2630-1. doi: $10.1161 / \mathrm{hc} 4701.100775$.

17. Islam AK, Majumder AA. Rheumatic fever and rheumatic heart disease in Bangladesh: A review. Indian Heart J. 2016 Jan-Feb;68(1):88-98. doi: 10.1016/j.ihj.2015.07.039.

18. Cheng Z, Fang Q, Liu Y. Cardiac amyloidosis with giant atria. Heart. 2010 Nov;96(22):1820. doi: 10.1136/hrt.2010.208066.

19. Yuksel UC, Kursaklioglu H, Celik T. Apical hypertrophic cardiomyopathy with giant left atrium. Arq Bras Cardiol. 2007 Feb;88(2):e47. English, Portuguese. doi: 10.1590/s0066-782x2007000200024.

20. Phua GC, Eng PC, Lim SL, et al. Beyond Ortner's syndrome-unusual pulmonary complications of the giant left atrium. Ann Acad Med Singap. 2005 Nov;34(10):642-5.

21. Brownsberger RJ, Morrelli HF. Hoarseness due to mitral valve prolapse. J Am Geriatr Soc. 1988 May;36(5):442-3. doi: 10.1111/j.1532-5415.1988.tb02384.x.

22. Black IW. Spontaneous echo contrast: where there's smoke there's fire. Echocardiography. 2000 May;17(4):373-82. doi: 10.1111/j.1540-8175.2000.tb01153.x.

Table 1. Clinical and echocardiographic profile of GLA patients $(\mathrm{N}=29)$

\begin{tabular}{lllllll}
\hline $\begin{array}{l}\text { Name, Age } \\
\text { (Y), Sex, } \\
\begin{array}{l}\text { Date of } \\
\text { first } \\
\text { contact }\end{array}\end{array}$ & Aetiology & ECG & LAD $(\mathbf{m m})$ & $\begin{array}{l}\text { LAVI } \\
\mathbf{m l} / \mathbf{m}^{\mathbf{2}}\end{array}$ & $\begin{array}{l}\text { Thrombus, } \\
\text { SEC }\end{array}$ & Comment \\
\hline $\begin{array}{l}\text { HA, } 26, \text { F } \\
15.04 .13\end{array}$ & RHD, severe & AF & 80 & - & SEC & $\begin{array}{l}\text { Died after } 4 \\
\text { years }\end{array}$
\end{tabular}




\begin{tabular}{|c|c|c|c|c|c|c|}
\hline $\begin{array}{l}\text { Name, Age } \\
(Y), \text { Sex, } \\
\text { Date of } \\
\text { first } \\
\text { contact }\end{array}$ & Aetiology & ECG & LAD (mm) & $\begin{array}{l}\mathrm{LAVI} \\
\mathrm{ml} / \mathrm{m}^{2}\end{array}$ & $\begin{array}{l}\text { Thrombus, } \\
\text { SEC }\end{array}$ & Comment \\
\hline $\begin{array}{l}\mathrm{PB}, 45, \mathrm{~F} \\
17.11 .14\end{array}$ & $\begin{array}{l}\text { RHD, severe } \\
\text { MS, mod MR, } \\
\text { mod AS, mod } \\
\text { AR }\end{array}$ & - & 120 & - & $\begin{array}{l}\text { SEC and } \\
\text { thrombus }\end{array}$ & Lost \\
\hline $\begin{array}{l}\mathrm{TB}, 55, \mathrm{~F} \\
15.06 .15\end{array}$ & $\begin{array}{l}\text { RHD, severe } \\
\text { MS }\end{array}$ & $\mathrm{AF}$ & 103 & - & Thrombus & Lost \\
\hline $\begin{array}{l}\mathrm{HR}, 29, \mathrm{M} \\
20.02 .18\end{array}$ & $\begin{array}{l}\text { RHD; Severe } \\
\text { MR, mod AS, } \\
\text { mod AR }\end{array}$ & $\mathrm{AF}$ & 109 & - & SEC & Lost \\
\hline $\begin{array}{l}\mathrm{MB}, 50, \mathrm{~F} \\
23.03 .18\end{array}$ & $\begin{array}{l}\text { RHD, severe } \\
\text { MS, mod MR }\end{array}$ & $\mathrm{AF}$ & 82 & - & Thrombus & $\begin{array}{l}\text { Died after } 2 \\
\text { year }\end{array}$ \\
\hline $\begin{array}{l}\mathrm{ZH}, 52, \mathrm{M} \\
16.08 .18\end{array}$ & $\begin{array}{l}\text { MVP, severe } \\
\text { MR }\end{array}$ & $\mathrm{AF}$ & 161 & - & None & Lost \\
\hline $\begin{array}{l}\text { SH, } 38, \mathrm{M} \\
12.01 .19\end{array}$ & $\begin{array}{l}\text { RHD, } \\
\text { post-MVR } \\
\text { stenosis, mild } \\
\text { MR }\end{array}$ & $\mathrm{AF}$ & 84 & - & None & Lost \\
\hline $\begin{array}{l}\mathrm{MB}, 33, \mathrm{M} \\
27.01 .19\end{array}$ & $\begin{array}{l}\text { RHD, mod } \\
\text { MS, severe } \\
\text { MR, severe } \\
\text { AR }\end{array}$ & $\mathrm{AF}$ & 80 & 214 & None & $\begin{array}{l}\text { Died after } 1 \\
\text { year, } \\
\text { post-DVR }\end{array}$ \\
\hline $\begin{array}{l}\text { RK, } 26, F \\
04.02 .19\end{array}$ & $\begin{array}{l}\text { MVP, severe } \\
\text { MR }\end{array}$ & Sinus rhythm & 87 & 269 & None & $\begin{array}{l}\text { Died after } 1 \\
\text { year }\end{array}$ \\
\hline $\begin{array}{l}\mathrm{MB}, 52, \mathrm{~F} \\
22.04 .19\end{array}$ & $\begin{array}{l}\text { RHD, severe } \\
\text { MS, severe } \\
\text { MR, mod AR }\end{array}$ & $\mathrm{AF}$ & 80 & 207 & None & $\begin{array}{l}\text { Died after } 1 \\
\text { year }\end{array}$ \\
\hline $\begin{array}{l}\mathrm{SD}, 55, \mathrm{M} \\
08.06 .19\end{array}$ & $\begin{array}{l}\text { RHD, severe } \\
\text { MS }\end{array}$ & $\mathrm{AF}$ & 86 & - & SEC & Alive \\
\hline $\begin{array}{l}\mathrm{SB}, 30, \mathrm{M} \\
12.06 .19\end{array}$ & $\begin{array}{l}\text { RHD, severe } \\
\text { MS, mod MR }\end{array}$ & $\mathrm{AF}$ & 83 & 196 & Thrombus & Lost \\
\hline $\begin{array}{l}\mathrm{NB}, 36, \mathrm{~F} \\
20.06 .19\end{array}$ & $\begin{array}{l}\text { Flail AML, } \\
\text { severe MR }\end{array}$ & $\mathrm{AF}$ & 81 & - & None & Lost \\
\hline $\mathrm{RB}, 35 . \mathrm{F}$ & $\begin{array}{l}\text { RHD, severe } \\
\text { MR }\end{array}$ & $\mathrm{AF}$ & 81 & 161 & None & Alive \\
\hline $\begin{array}{l}\text { TK, 16, F } \\
11.07 .19\end{array}$ & $\begin{array}{l}\text { MVP, severe } \\
\text { MR }\end{array}$ & Sinus rhythm & 82 & - & None & Lost \\
\hline $\begin{array}{l}\mathrm{SB}, 26, \mathrm{~F} \\
02.10 .19\end{array}$ & $\begin{array}{l}\text { RHD, severe } \\
\text { MR }\end{array}$ & - & 89 & - & None & Lost \\
\hline $\begin{array}{l}\text { BK, 24, M } \\
11.11 .19\end{array}$ & $\begin{array}{l}\text { MVP, severe } \\
\text { MR }\end{array}$ & $\mathrm{AF}$ & 82 & 254 & None & Lost \\
\hline $\begin{array}{l}\text { SN, } 50, \mathrm{~F} \\
22.02 .20\end{array}$ & $\begin{array}{l}\text { RHD, severe } \\
\text { MS, mod MR }\end{array}$ & $\mathrm{AF}$ & 105 & - & SEC & Lost \\
\hline $\begin{array}{l}\text { SK, } 28, F \\
24.02 .20\end{array}$ & $\begin{array}{l}\text { RHD, severe } \\
\text { MS, severe } \\
\text { MR, mild AR }\end{array}$ & $\mathrm{AF}$ & 96 & - & SEC & Lost \\
\hline
\end{tabular}




\begin{tabular}{|c|c|c|c|c|c|c|}
\hline $\begin{array}{l}\text { Name, Age } \\
(Y), \text { Sex, } \\
\text { Date of } \\
\text { first } \\
\text { contact }\end{array}$ & Aetiology & ECG & LAD (mm) & $\begin{array}{l}\mathrm{LAVI} \\
\mathrm{ml} / \mathrm{m}^{2}\end{array}$ & $\begin{array}{l}\text { Thrombus, } \\
\text { SEC }\end{array}$ & Comment \\
\hline $\begin{array}{l}\text { NI, } 59, \mathrm{~F} \\
27.09 .20\end{array}$ & $\begin{array}{l}\text { MVP, severe } \\
\text { MR }\end{array}$ & $\mathrm{AF}$ & 94 & 319 & None & Alive \\
\hline $\begin{array}{l}\text { SM, 19, M } \\
03.10 .20\end{array}$ & $\begin{array}{l}\text { MVP, severe } \\
\text { MR }\end{array}$ & $\mathrm{AF}$ & 113 & 463 & None & Lost \\
\hline $\begin{array}{l}\mathrm{TZ}, 35, \mathrm{M} \\
21.11 .20\end{array}$ & $\begin{array}{l}\text { Post-MVR } \\
\text { severe MR, } \\
\bmod \text { AR }\end{array}$ & $\mathrm{AF}$ & 94 & 605 & SEC & Lost \\
\hline $\begin{array}{l}\mathrm{SH}, 44, \mathrm{M} \\
02.12 .20\end{array}$ & $\begin{array}{l}\text { RHD, } \\
\text { post-MVR, } \\
\text { mild AR, } \\
\text { DCM }\end{array}$ & $\mathrm{AF}$ & 91 & 194 & None & Alive \\
\hline $\begin{array}{l}\mathrm{HB}, 42, \mathrm{~F} \\
05.12 .20\end{array}$ & $\begin{array}{l}\text { MVP, severe } \\
\text { MR }\end{array}$ & Sinus rhythm & 101 & 273 & None & Lost \\
\hline $\begin{array}{l}\text { AK, } 45, \\
\text { F08.12.20 }\end{array}$ & $\begin{array}{l}\text { RHD, } \\
\text { post-CMC } \\
\text { severe MS, } \\
\text { severe MR, } \\
\text { mild AS, } \\
\text { mod AR }\end{array}$ & $\mathrm{AF}$ & 82 & 224 & Thrombus & $\begin{array}{l}\text { Alive, } \\
\text { recently had } \\
\text { DVR }\end{array}$ \\
\hline $\begin{array}{l}\text { SY, 38, F } \\
30.01 .21\end{array}$ & $\begin{array}{l}\text { RHD, } \\
\text { post-PTMC } \\
\text { severe MS, } \\
\text { severe MR }\end{array}$ & $\begin{array}{l}\text { Paroxysmal } \\
\text { AF }\end{array}$ & 81 & 171 & None & Alive \\
\hline $\begin{array}{l}\mathrm{NB}, 26, \mathrm{~F} \\
18.03 .21\end{array}$ & $\begin{array}{l}\text { RHD, mod } \\
\text { MS, severe } \\
\text { MR, mild AS, } \\
\text { mod AR }\end{array}$ & $\mathrm{AF}$ & 81 & 221 & None & Live \\
\hline $\begin{array}{l}\mathrm{SH}, 40, \mathrm{M} \\
28.03 .21\end{array}$ & $\begin{array}{l}\text { RHD, mod } \\
\text { MS, severe } \\
\text { MR, DCM }\end{array}$ & $\mathrm{AF}$ & 81 & 183 & Thrombus & Alive \\
\hline $\begin{array}{l}\mathrm{MH}, 41, \mathrm{M} \\
20.04 .21\end{array}$ & $\begin{array}{l}\text { RHD, severe } \\
\text { MR }\end{array}$ & $\mathrm{AF}$ & 91 & 584 & None & $\begin{array}{l}\text { Live, waiting } \\
\text { for MVR }\end{array}$ \\
\hline $\begin{array}{l}\text { MA, } 35, \text { M } \\
24.05 .21\end{array}$ & $\begin{array}{l}\text { RHD, severe } \\
\text { MS, severe } \\
\text { MR, mid } \\
\text { AR }\end{array}$ & $\mathrm{AF}$ & 84 & 371 & $\begin{array}{l}\text { SEC and } \\
\text { thrombus }\end{array}$ & $\begin{array}{l}\text { Live, waiting } \\
\text { for MVR }\end{array}$ \\
\hline
\end{tabular}

GLA, giant left atrium; ECG, electrocardiography; LAD, left atrial diameter; LAVI, left atrial volume index; SEC, spontaneous echo contrast; RHD, rheumatic heart disease; MS, mitral stenosis; MR, mitral regurgitation; AS, aortic stenosis; AR, aortic regurgitation; mod, moderate; MVP, mitral valve prolapse; AML, anterior mitral leaflet; DCM, dilated cardiomyopathy; PTMC, percutaneous transvenous mitral commissurotomy; MVR, mitral valve replacement; DVR, double valve replacement; AF, atrial fibrillation.

Figure 1. Giant left atrium in a patient with rheumatic mitral valvular disease. Panel A, M-mode echocardiography showing dilated left atrium with left atrial diameter $81 \mathrm{~mm}$. Panel B, 2D echocardiography left parasternal short axis view showing moderate mitral stenosis (yellow arrow) with mitral valve area $1.5 \mathrm{~cm}^{2}$. 
Panel C and D, 2D echocardiography apical 4-chamber view showing left atrial volume index of $221 \mathrm{ml} / \mathrm{m}^{2}$. Abbreviation: $\mathrm{LA}=$ left atrium, $\mathrm{RA}=$ right atrium, $\mathrm{LV}=$ left ventricle, $\mathrm{RV}=$ right ventricle, $\mathrm{LAVI}=$ left atrial volume index.

Figure 2. Giant left atrium in a patient with mitral valve prolapse. Panel A, chest x-ray posteroanterior view showing huge cardiomegaly with the right cardiac border touching the right chest wall (black arrow). Panel B, 2D echocardiography left parasternal long-axis view showing prolapse of both leaflets of the mitral valve (yellow arrows) with non-coaptation (green arrow). Panel C, 2D-guided colour Doppler echocardiography apical 4-chamber view showing severe mitral regurgitation (green arrow). Abbreviation: LA = left atrium, $\mathrm{LV}=$ left ventricle, $\mathrm{AML}=$ anterior mitral leaflet, $\mathrm{PML}=$ posterior mitral leaflet.

Figure 3. Giant left atrium in a patient with isolated mitral stenosis. Panel A, 2D echocardiography left parasternal long-axis view showing features of severe mitral stenosis. Panel B, 2D-echocardiography apical 4-chamber view showing hugely dilated left atrium. Both panels A and B show dense spontaneous echo contrast in the left atrial cavity, hiding accompanying thrombus which was extracted per-operatively. Abbreviation: $\mathrm{LA}=$ left atrium, $\mathrm{RA}=$ right atrium.
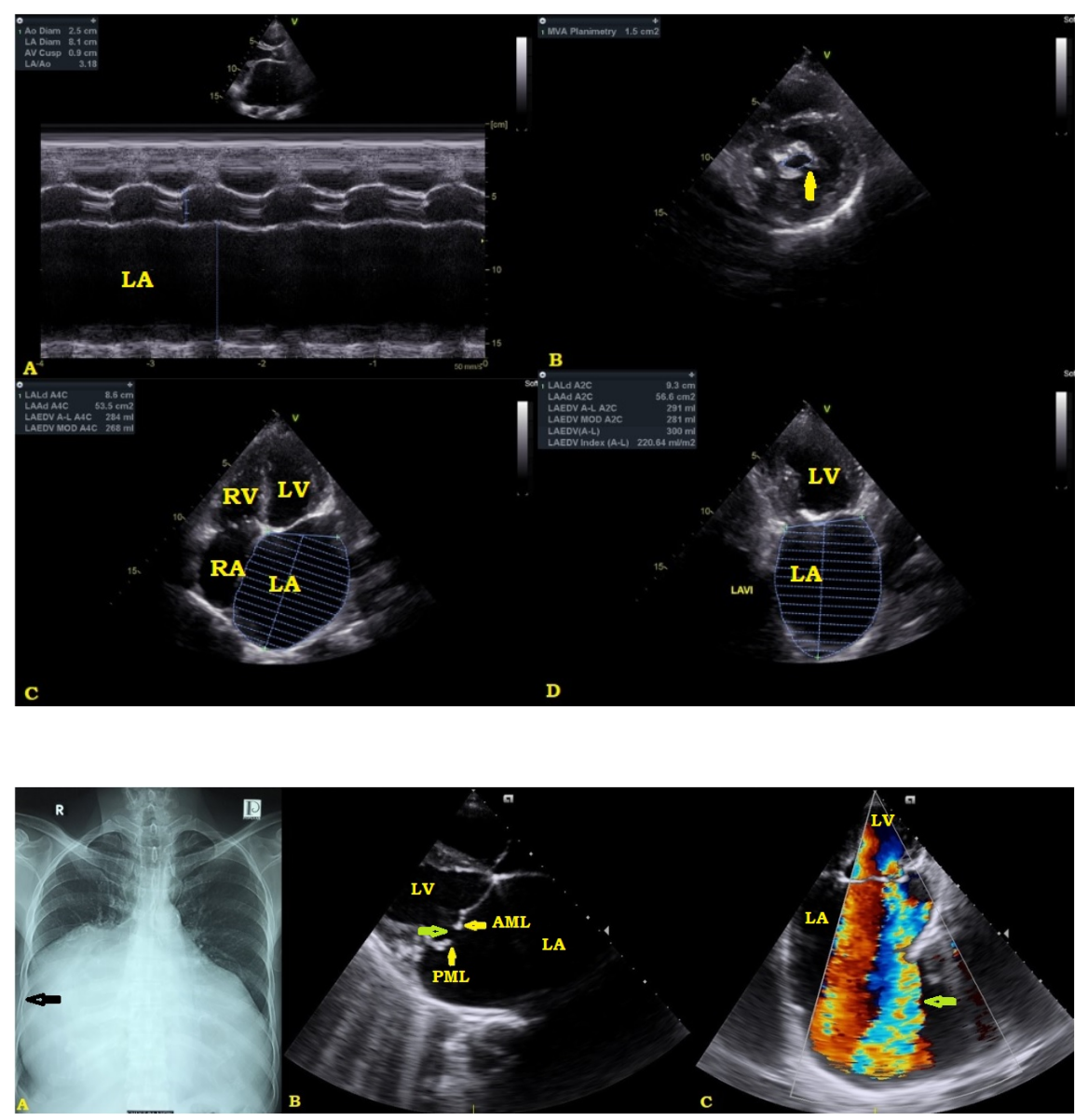


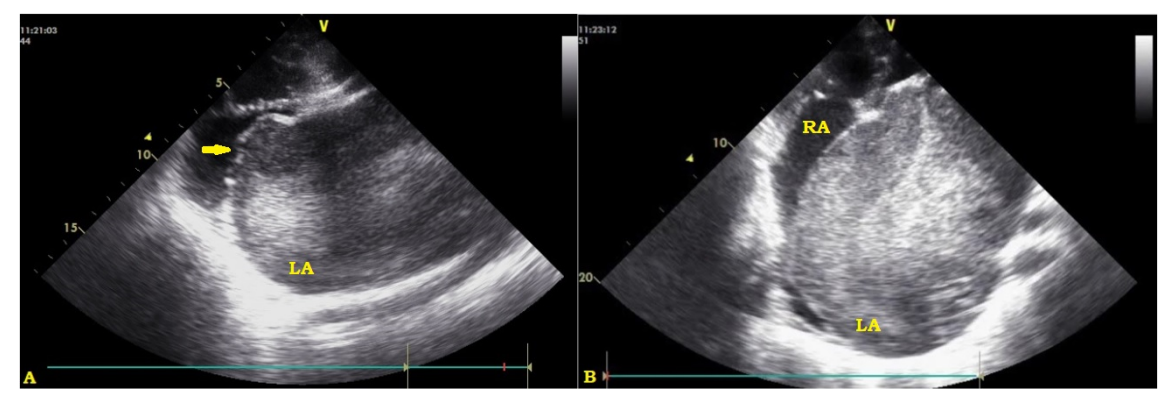

